\title{
Product-Service Systems Modelling and Simulation as a Strategic Diagnosis Tool
}

\author{
Thècle Alix and Gregory Zacharewicz \\ Univ. Bordeaux, IMS, UMR 5218, F-33400 Talence, France, \\ CNRS, IMS, UMR 5218, F-33400 Talence, France \\ firstname.namedims-bordeaux. fr
}

\begin{abstract}
Manufacturers have developed Product/Service-Systems (PSS) strategies to increase their competitiveness and reach objectives of profitability, satisfying customer's specific and evolving needs as well as environmental needs in term of grasp reduction and pollution decrease. Despite, the announced success of such a strategy, industrialists fears that the strategy will not give the expected results. To avoid unsustainable developments and reach productservice systems features, manufacturers are looking forward methods and tools that can help them predicting an a priori level of performance of the whole system they intend to design in terms of sustainability, use, profit, etc. Precisely, we aim at proposing a demonstrator able to support decision in the design of new sustainable and eco-efficient product-service system.
\end{abstract}

Keywords: Product/Service-System, PSS modelling, PSS simulation, diagnosis tool.

\section{Introduction}

The individual and collective awareness of the huge importance of environmental issues led politics, researchers, and citizens to focus on sustainable production and consumption. Some of the most indicative incentives are focusing on green economy, circular economy, function-oriented business model, industrial ecology, functional service economy, etc. A common call is the need for a new strategy to stimulate the change in current production and consumption patterns. According to some statements, rising levels of consumption by the rich and doubling of the world population over the next 50 years would require a factor 4 increase in food production and a factor 6 increase in energy use. An estimate mentions that by the middle of the century, global consumption of natural resources could triple if the coupling between economic growth and the rate of natural resource consumption remains as it is. Theories are developed about the factor by which the environmental performance can be improved. Solutions are devised to support the change around reducing the population, lowering the level of consumption or changing technology.

The first option is not feasible in the short term. The second one: decreasing consumption levels does not appear to be a simple option either because, on the one hand, people from industrialised countries do not show any obvious willingness to 
minimise consumption and, on the other hand, there is a need to increase consumption levels in developing countries just to provide basic amenities. The third option: changing technology is a matter of considerable study as it concerns the branch of knowledge that deals with the creation and use of technical means and their interrelation with life, society, and the environment, drawing upon such subjects as industrial arts, engineering, applied science, and pure science. In pragmatic way, technology gather knowledge and practises used to provide customers with products and services.

The service growing need driven by the market gradually led the service sector to dominate the economy and to be the lifeblood of job creation. Partly unsatisfied, service demand, perceived by the society as a way to have access to basic or complex amenities, is of prime importance while the product demand becomes secondary. This prompted the secondary industry to consider service activities as a potential source of benefits [1]. At the same time the increasingly aggressive competition in the service sector challenged service industrialization and more and more service providers attempted to include a product in their offer.

As a result, the boundary between products and services get blurred [2]. Mixing product and service demand, socio-economic, technologic and environmental constraints and statements combinations of product (physical artefact) and service (functionality from the product or added expected by the customer regarding his needs and product usage) under different denomination have been developed [3]. Variants come from the focus: economic (variety of business model [4], technological (functional engineering), commercial (new ownership pattern [5]), environmental, etc. The System resulting from the combination Product(s) and Service(s) (PSS) extends the traditional functionality of a product by integrating additional services giving emphasis on the 'sale of use' rather than the 'sale of product'. PSS are also supposed to have positive impacts in terms of sustainability, by the reduction of resource and/or energy consumption.

PSS design and development, result in a matter of huge importance. To avoid unsustainable developments, manufacturers are looking forward for methods and tools that can help them in predicting the level of performance the whole system they intend to design would reach. We propose to use simulation to calculate that level of performance and assume that as simulation is based on modelling, the first step is to propose a PSS modelling to have a complete description of the components of a PSS, the links between them and with performance criteria associated to the design of new sustainable and eco-efficient services system. The main focus of the article is on modelling. After a prompt recall of PSS concepts, an overview of the status of modelling and simulation research is presented. The fourth part presents our vision for PSS modelling and simulation before concluding.

\section{$2 \quad$ PSS Complexity as a Response to the Society, Customers and Manufacturers Awareness}

A PSS is "Product(s) and service(s) combined in a system to deliver required user functionality in a way that reduces the impact on the environment" [7]. The definition 
extended through the years acknowledges that the concept of PSS also embraces value in use and sustainability [8], [9]). PSS appear to be a possible and promising business strategy which can achieve the leap that is needed to move to sustainable society. PSS development is therefore concerned with satisfying customer, society and company in providing the latter with a closer contact to the user and a possibility to get new market opportunities by exploiting the knowledge from the contact. Despite an undeniable interest, the willingness of manufacturers to move to that business strategy is challenged by their ability to create value added [6], and to make direct and indirect profit. The literature mentions many flops to this end. Furthermore, as there exists lot of variants, it is not clear which variant is to develop and if it is really sustainable and profitable.

In addition, even if advices were given to manufacturers to simultaneously consider products and services, industrial developments are mainly product-centric. Services and their performances (value in-use) and characteristics (customer-centric) are developed in a second phase according to options offered by products. The system pushed at the customer is not properly appreciated. Innovation aimed at increasing customer satisfaction does not find an echo and company return on investment is negligible. In addition, each system is unique and does not benefit from the experience of previous systems. Moreover new resources are each time consumed. To achieve the goal of sustainability, the strategy requires considering simultaneously industrial and service developments.

Furthermore, economically the return on investment of the different systems proposed by the firms is mostly calculated a posteriori, i.e. once the system is set up and delivered to the customers rather than being identified and anticipated a priori. This sometimes leads to wrong system specifications and practices that penalize the enterprise such as misleading coupling between products and services.

PSS developments face many challenges: sustainability, value, economy of use, profitability, etc. A first step towards sustainability is to use virtual testing to determine the ability of different product and service components having common features to interoperate to create value. Virtual testing enables to modify product and service configurations and give results without any physical resource intensive realization. Then, our contribution does not concern PSS design for which a wide range of tools and methodologies are proposed. The action is upstream in PSS life cycle innovation and concerns the ideation phase. Objective is to help project managers to determine among potential innovations the most relevant one.

\section{Status of PSS Modelling and Simulation Research}

PSS Simulation is an emerging field suffering from a lack of background and unanimous knowledge in its essential: the service and the service modelling [10]. Many authors describe modelling and simulation as one process, assessing that modelling is a sort of prerequisite for simulation and not an activity by itself. 


\subsection{Service and PSS Modelling}

Due to the varying definitions and characteristics of the term service, service modelling has not yet adopted a unique common standard for developing frameworks to manage services processes. Even if simulation has been used to model manufacturing systems and specific service systems (banking, healthcare hospitality, etc.) and sometimes in modelling business operations of both systems, characteristics of each system need to be taken into account [11].

Furthermore, the specification of Service Modelling can involve different process, application and actor components, which are essential to the service execution, but heterogeneous. The specification standards are numerous. Becker reports more than 15 main reference models [12]. Some authors transpose to service the administrative or production workflow process sequence description [13]. Others use the graphical definition of a Service-Oriented Modelling Framework (SOMF) [14]. An essential breach concerns the model correctness checking. The W3C proposed an XML representation of Service Modelling Language (SML) accepted as a standard in the Service modelling community. Service Modelling Language (SML) and Service Modelling Language Interchange Format (SML-IF) [15] are a pair of XML-based specifications created by leading information technology companies that define a set of XML instance document extensions for expressing links between elements, a set of XML Schema extensions for constraining those links, and a way to associate Schematron rules with global element declarations, global complex type definitions, and/or model documents. It is to note that the proposed description is more Computer Science Service Modelling oriented than PSS oriented.

\subsection{PSS Simulation}

Only few contributions to simulation of PSS have emerged since 2000. Most of the projects performed over the past decade focused the dynamic behaviour of the PSS process and were mainly driven by the goal to provide feedbacks to designers to support the design of a relevant model of the system and to verify some desired properties.

In the literature, Bianchi has chosen the system dynamic methodology for PSS simulation [16]. The methodology allows analysing the dynamic of a PSS strategy managing interrelated factors features by non-linear complex dynamics and negative/positive reinforcement loops. The approach is serious game to support a hypothetical organization to invest or not in a PSS strategy depending it will be generating welfares or not. The model takes into account four possible stakeholders (government, Product-Oriented Manufacturers, PSS providers and consumers), some market parameters, strategic policies, capacity of PSS transition for PO, etc. [17]. The main advantage of the method lies in the easy combination with others (i.e. multi criteria approach) to provide decision support systems.

Bulk simulation is another simulation method that allows considering simultaneously many parameters and characteristics that are simulated in batch [18]. Van der Vegte proposes in [19] to simulate at the level of interaction sequences, in a 
non-interactive fashion and with consideration of multiplicity the use of informationintensive products and PSS in design. Designers can investigate the use of a product over a long time or massive batches of smaller intervals of use and then predict outcomes of use during design. Bulk simulation proposes to model stakeholders (users and service providers) as well as products as individual agents.

Agent based simulation is a wide used simulation technique to model a system as a pool of autonomous decision-maker agents. The simulation results are produces by and their interactions [20]. The assumption is that the global system behaviour can be studied based on the M\&S of individual behaviour and their interactions.

Others studies focus on Discrete-Event System simulation [21]. The structural components of a PSS discrete-event simulation typically include: model entities, model activities, model resources and model layout. Simulators based on that technic can be used to increase the added value of the system companies might design. The different researches identify the variables to be followed during simulation including the price, process costs lifetime, sales frequency, lifetime, etc. In [22] the simulation was running customer behaviour in term of buying habits. The results were giving feedbacks on the comparison between buying goods and using PSS. But none of the current research works specifically focus on customer use, sustainability and synergies between products and services in the PSS context.

\subsection{Few Findings to Focus on}

The literature review leads to the following conclusions:

- There is no unanimous reference model of a PSS and a fortiori no modelling language dedicated to PSS. Objective is to propose a generic PSS model based on constructs that can be instantiated according to particular cases.

- Modelling and simulation are most of the time integrated in one thought leading to underestimate the difficulties inherent to service modelling and to position upstream problematic specific to the time dependency of the system to model. We propose to distinguish the two steps and consequently to first model a PSS and then simulate the model.

- A PSS is a sequence of multiple, interrelated life phases and activities throughout the product's service time [23]. Both static and dynamic models are mandatory to have a complete representation of a PSS.

- Two main kinds of studies are supported by simulation: the identification of the added value of systems manufacturers intent to develop, the determination of the profit a design can lead to. Added value is the main consumer concern while profit is the manufacturer concern. As these two elements are of huge importance and dependent, the simulation must support value and profit analysis i.e. a customer perspective and a manufacturer one.

- Stakeholders are taken into account in all models and PSS life cycle needs to be considered carefully.

- Product usage is important and is not taken into account in all models. Usage can give information on the sustainability of the product as a behavioural performance indicator enabling to get knowledge to design lean PSS and to increase the system added value. 
- Adaptability to the customer environment is to be analysed and the product might be integrated in the value added process of the customer. The PSS reference modelling based on UML modelling is depicted in next section.

\section{$4 \quad$ Methodology for Service Modelling}

\subsection{Modelling Principles}

The PSS modelling is based on the following assumptions.

- Three stakeholders are interested in the "success" of new PSS design and development: the provider of the system, the customer and the society (eco-system).

- PSS are designed to respond to customers' usage requirements defined a priori (i.e. before the system is delivered to customer) and combine products and services. Each product can be described through functions designed to fit service requirements. Each PSS designed and delivered can then be seen as a unique complex set composed of products subsets (tangible component) and services subsets (intangible components). Components are structured in modules having functionalities. These functionalities allow some usages that can be challenged to customers' specific usage needs (identified a priori or a posteriori). The gap between both influences the PSS value perceived by the customer. Modules can be combined differently according to specific usage needs and lead to PSS variants. Variants objective is to increase the value perceived by customers.

- PSS providers design PSS processes supported by resources, with the aim of generating profit. Profit is maximized when PSS value is high and resource consumption of the PSS process low. Obviously variants modify processes and decrease profitability. Furthermore, variants impact resource consumption.

- Finally, society put pressure on the environmental impact of new development. Accordingly, functionality and resource consumption have to respect ecosystem requirements in terms of sustainability.

The resulting PSS modelling is depicted in figure 1. Each functionality can be described through its components and characterized by attributes: cost, environmental impact, associated usage, or else resource needs to deliver the functionality. Attributes are described from a qualitative and quantitative point of view. Once the description is complete, the functionality can integrate a library and potential coupling with other functionality can be virtually tested.

\subsection{Simulation Principles}

New PSS design and development is based on a strategic analysis whose objective is to define lines of innovation. Most of the time, innovations are incremental - series of small steps - as enterprises find ways to update their products and processes or to integrate basic services. Simulation principle is to analyse the possibility that new functionalities supplement a PSS existing ones while receiving benefits, if any, of 
components already used to fill these existing functionalities. Specifically, the assembly of components can be simulated in order to measure their capacity to easily interact and to cope with the customers' need and use, with the manufacturers' profit expectations and with the environmental incentive. The simulation of scenario tests can give clue to manufacturers to develop and set up a win-win strategy for them, their customers and the environment.

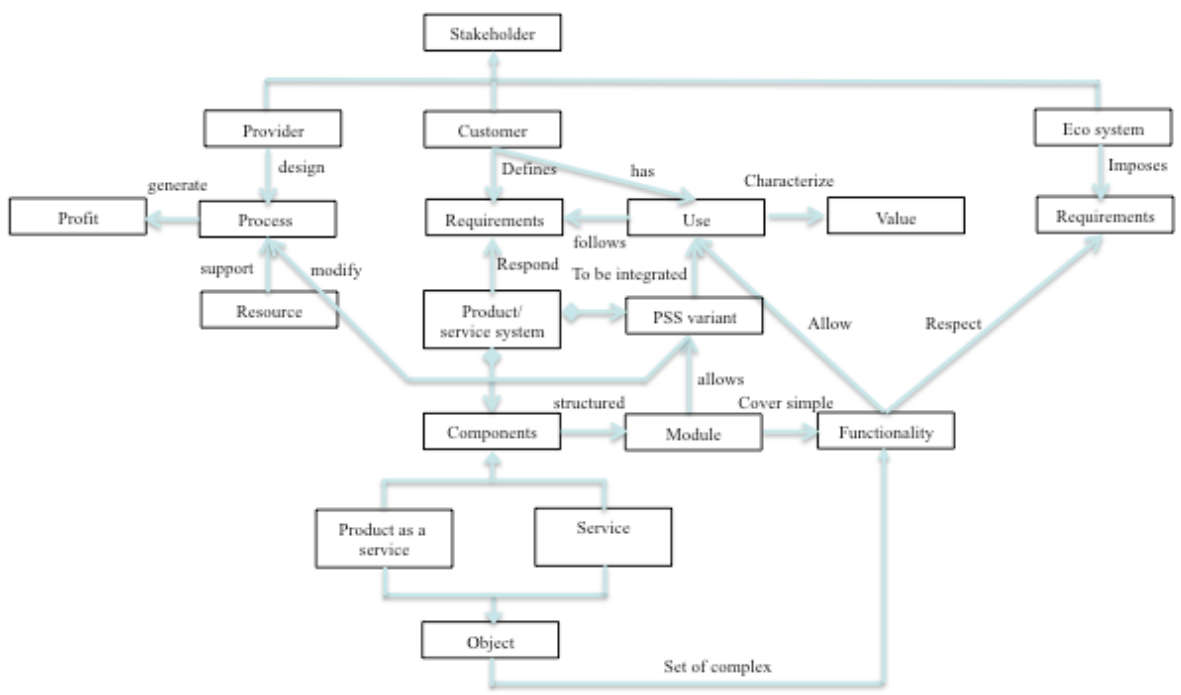

Fig. 1. Product Service System modelling for eco-efficient design

\section{Conclusion}

The design and development of product-service systems is a hot topic regarding its economic and societal impact. Although successful designs are mentioned in the literature, many flops exist and disrupt the willingness of manufacturers to innovate in that sense. Objective of our works is to use simulation as a decision aid tool in the design of new sustainable and eco-efficient product-service system. A first step to reach that objective consists in modelling a PSS. This modelling represents the main contribution of this article. The following step is to quantify attributes of functionalities and components; investigations on best compromise or optimization strategies for building services in awareness of both enterprises and customer needs, and environmental impact and societal value have to be conducted. A simulator is then to be developed.

The authors trust that defining key performance indicators to follow regarding dynamic of the PSS delivery process the simulation is a promising technic that can help to PSS designer to anticipate problems and to dimension properly the offer regarding client's requirements. It will anticipate claims and increase client loyalty. 


\section{References}

1. Oliva, R., Kallenberg, R.: Managing the transition from products to services. International Journal Service Industrial Management 14(2), 160-171 (2003)

2. Mont, O.: Product-service systems: Panacea or myth? PhD thesis, The International Institute for Industrial Environmental Economics. Lund University, Sweden (2004)

3. Sundin, E.: Life-Cycle Perspectives of Product/Service- Systems: in Design Theory. In: Introduction to Product/Service-System Design. Springer (2009)

4. Hockerts, K.: Eco-Efficient Service Innovation: Increasing Business-Ecological Efficiency of Products and Services. In: Charter, M. (ed.) Greener Marketing: A Global Perspective on Greener Marketing Practice, Sheffield, UK (2007)

5. Meijkamp, R.: Changing Consumer Behaviour Through Eco-efficient Services: an empirical study on car sharing in the Netherlands. Delft University of Technology, Delft, The Netherlands (2000)

6. Tukker, A.: Eight types of productservice system: eight ways to sustainability? Experiences from suspronet. Business Strategy and the Environment 13, 246-260 (2004)

7. Tukker, A., Tischner, U.: New Business for Old Europe. Greenleaf Publishing (2006)

8. Goedkoop, M.J., van Halen, C.J.G., Riele, H.R.M., Rommens, P.J.M.: Product Service Systems, Ecological and Economic Basis. Pricewaterhouse Coopers N.V. / Pi!MC, Storrm C.S., Pre consultants (1999)

9. Stahel, W.: The Performance Economy. Palgrave Macmillan (2006)

10. Touzi, W.: Conceptualisation et modélisation de la production de service: application aux domaines de la santé et de l'enseignement. Thèse de doctorat, Université Bordeau 1 (2001)

11. Lovelock, C., Wirtz, J., Lapert, D.: Marketing des services. Pearson Education (2004)

12. Becker, J., Beverungen, D.F., Knackstedt, R.: The challenge of conceptual modelling for product-service systems: status quo and perspectives for reference models and modelling languages. Information Systems and E-Business Management Journal 8(1), 33-66 (2010)

13. Meier, H., Roy, R., Seliger, G.: Industrial Product-Service Systems-IPS2. CIRP Annals Manufacturing Technology 59(2), 607-627 (2010)

14. Bell, M.: Service-Oriented Modelling: Service Analysis, Design, and Architecture. John Wiley \& Sons, Inc., Hoboken (2008)

15. http://www.w3.org/TR/sml/

16. Bianchi, N.P.: Influencing factors of successful Transitions towards product-Service Systems: a simulation approach. International Journal of Mathematics and Computers in Simulation 3(1) (2009)

17. Sterman, J.D.: Business dynamics: systems thinking and modelling for a complex world. Irwin McGraw Hill (2000)

18. Wile, B., Goss, J.C., Roesner, W.: Comprehensive functional verification the complete industry cycle. Morgan Kaufmann (2005)

19. Van der Vegte, W.F., Horvath, I.: Bulk simulation of using information intensive products and product-service systems: formal underpinnings. In: Proceeding of TMCE 2012 (2012)

20. Bonabeau, E.: Agent-based modelling: Methods and techniques for simulating human systems. Proceedings Natl. Acad. Sci. USA, 280-7287 (2002)

21. Phumbua, S., Tjahjono, B.: Simulation Modelling of Availability Contracts. In: Simulation Modelling of Product-Services Systems: The missing Link, MATADOR Conference (2010)

22. Alix, T., Zacharewicz, G.: Product-service systems scenarios simulation based on GDEVS/HLA: Generalized discrete event specification/high level architecture. Computers In Industry 63(4), 370-378 (2012) 